\title{
前交通動脈開空内に発育した破裂動脈瘤手術法の検討
}

\author{
岡部 慎一, 日野 健, 鄭莉婭, 原田 洋一 \\ 藤井 芳樹, 河野 拓司, 鎌田 健一
}

\section{Operative Problems of the Ruptured Aneurysm Growing in the Fenestration of the Anterior Communicating Artery}

Shinichi Okabe, M.D., Ken Hino, M.D., Liya Zheng, M.D., Yoichi Harada, M.D., Yoshiki Fujir, M.D., Takuji Kohno, M.D., and Kenichi Kamata, M.D.

Seirei Memorial Hospital for Neurosurgery, Hitachi, Japan

Summary : We report 3 cases of the ruptured anterior communicating artery aneurysm growing in the fenestration of the anterior communicating artery $(\mathrm{ACoA})$. In preoperative angiography, it was difficult to demonstrate the whole images of an aneurysm including the neck. The body of an aneurysm was partially divided by the distal ACoA. The posterior part of an aneurysm is larger than the anterior one and projected posteriorly in all cases. The distal ACoA made a string with no blood flow in 2 cases.

In the operation, the neck dissection is relatively difficult because of the existence of the distal $\mathrm{ACoA}$ near the neck of the aneurysm. It was necessary to cut the distal ACoA in 1 case and trap the right $\mathrm{A} 1$ portion with the aneurysm in another case. The body of an aneurysm was clipped on each side of the fenestration in the other case.

These aneurysms with the fenestration of the ACoA were considered to be difficult for clipping. Great care must be taken to clipping procedures for the complete obliteration of such aneurysms.

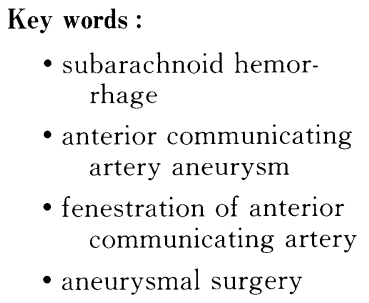
artery aneurysm

- fenestration of anterior communicating artery

- aneurysmal surgery

$$
\text { はじめに }
$$

前大脳動脈に関連する血管破格は多く報告されており, 動脈瘤手術時に前交通動脈 $(\mathrm{ACoA})$ の開空形成に遭遇する ことはまれではない。しかしながら，その開空内に破裂動 脈瘤が発育し，柄部処置に関して問題になったという報告 は少ない。最近, 我々はこのような動脈瘤が原因となった クモ膜下出血 3 例を経験し, 手術時の注意点を含め, 若干 の知見を得たので報告する.
症例

$<$ 症例 $1>48$ 歳, 女性.

H\&K Grade I, Fisher CT Group 2, day 1 で手術を施 行.

術前の血管撮影では，後上方に突出する前交通動脈瘤を 認めたが，開空形成は確認できなかった(Fig. 1A). 右 pterional approachにより手術を施行した. ACoAの部分 には開空形成を認め, distal ACoA は索状になっており, 動脈瘤の体部はそれにより, 前後に分かれ, 後方部分が大

脳神経外科 聖麗メモリアル病院(受稿日 1995.10.25)〔連絡先：テ316 日立市中成沢町 1-16-10 脳神経外科聖麗メモリアル病院 岡部慎一] [Mailing address: Shinichi OKABE, M.D., Seirei Memorial Hospital for Neurosurgery, 1-16-10 Nakanarusawa-cho, Hitachi 316, Japan] 
きく後方に突出していた (Fig. 2). Distal ACoA の存在に より, 柄部剥離は困難であったため, 両側 A1に temporary clip をかけ, distal ACoA を切断した. しかし, 動脈 瘤は proximal ACoA 全体から発育した形をして㧍り, 柄 部剝離は困難で, 柄部付近からの小出血がみられたため, 右 $\mathrm{A} 2$ をまたぎ，開空クリップにて，proximal ACoA を 形成するようにクリッピングした．右 Heubner's artery, ACoA からの視床下部穿通枝は温存を確認した．血管撮 影で動脈瘤は消失していた(Fig. 5A)。術後 MRI で右尾状 核頭部に梗塞巣を認めたが, 神経脱落症状なく退院した。

<症例 2> 56 歳, 男性.

H\&K Grade I, Fisher CT Group 2, day 1 で手術を施 行.

術前の血管撮影で後上方に突出する前交通動脈瘤を認め た. 前床突起から動脈瘤柄部まで $1 \mathrm{~cm}$ の高位動脈瘤であ った(Fig. 1B). 左 pterional approachで手術を施行した. $\mathrm{ACoA}$ の distal にも索状の $\mathrm{ACoA}$ を認め, 破裂動脈瘤は 両 A2 の後方に突出していた，2本の ACoA の間から前 方に blister 様の動脈瘤を認めた (Fig. 3)。索状 ACoA は 柄部近傍にあり, 前後に動脈瘤が分かれているため, 切断 しても，1本のクリップで同時に処置できるとは考元難く, 索状の ACoA はそのままにして, 両動脈瘤とも別々にク リッピングを施行した，血管撮影で動脈瘤は消失していた (Fig. 5B). 術後, 特に問題なく経過し, 神経脱落症状な く退院した.

$<$ 症例 3 > 40 歳, 女性.

H\&K Grade III，Fisher CT Group 3, day 0 で手術を施 行.

術前の血管撮影では，動脈瘤が後方に発育しているため $\mathrm{ACoA}, \mathrm{A} 1$ 部と重なり，全貌を描出することはできず, また，開空形成も確認はできなかった。優位側 $\mathrm{A} 1$ は右で あった(Fig. 1C). 右 pterional approach にて手術を施行 した， ACoA は開空形成しており，動脈瘤は柄部を開空 内において, 右側の $\mathrm{A} 1$ 側に持つと思われ, 動脈瘤体部は 開空内に完全にはまりこんでいた，開空の前方よりも，後 方に大きな体部を認め, 柄部は広頸であると思われた (Fig. 4). 開空部分から動脈瘤体部を剝離中に出血をきた したため, 開空内から柄部を完全に剝離するのは困難であ ると判断し, 右 $\mathrm{Al}$, proximal $\mathrm{ACoA}$, distal $\mathrm{ACoA}$ と柄部 の間，の 3 カ所にクリップをかけ, 動脈瘤への血流を完全 に遮断した。この操作により, A2 以降の左右前大脳動脈 血流は右側より細い左 A1 からのみ供給されることになっ た. 血管撮影で動脈瘤は消失していた (Fig. 5C)。術後, 1 カ月程度両下肢の麻㿎が継続したが徐々に回復, 独歩可

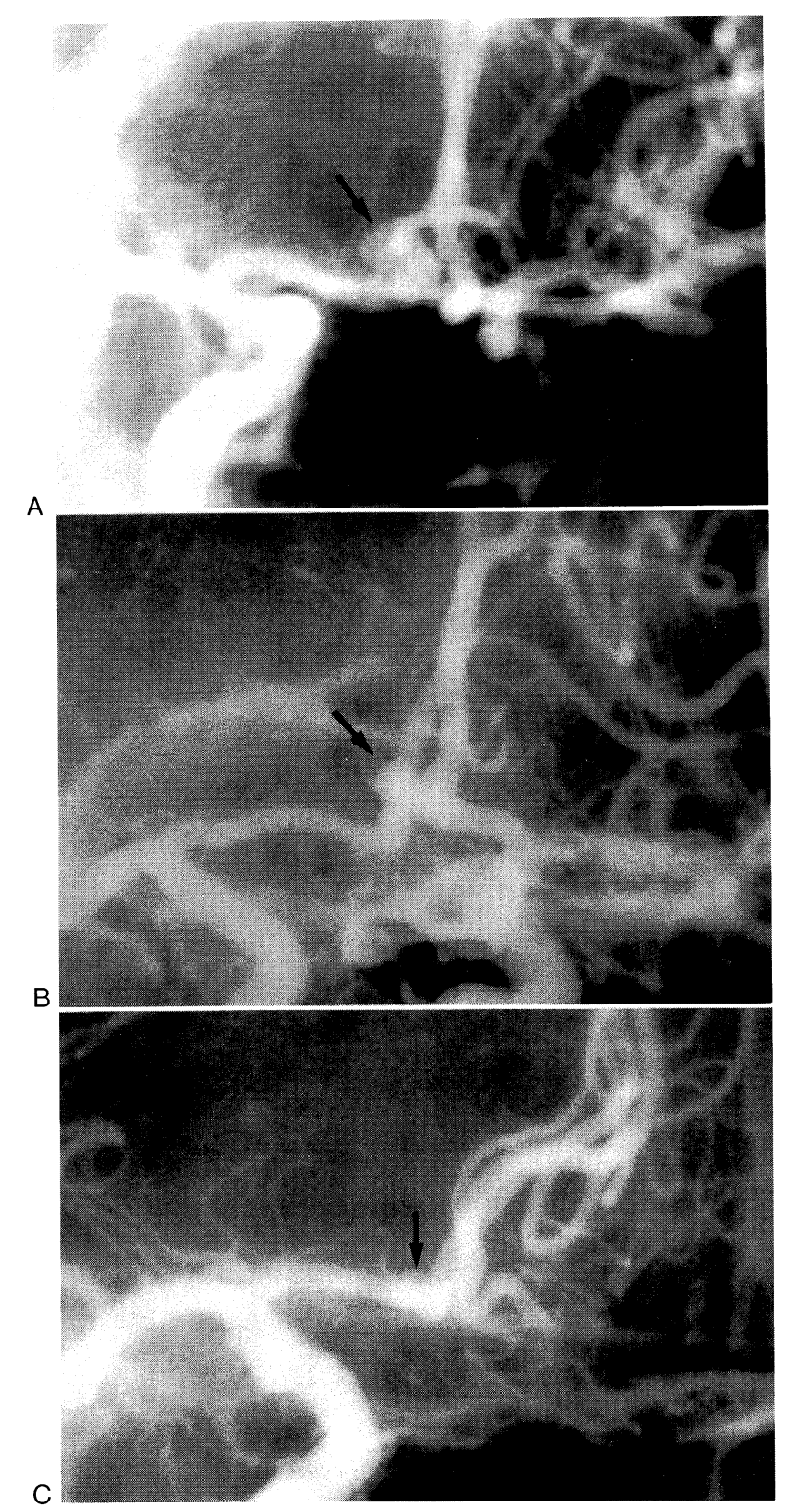

Fig. 1 Right anterior oblique views of carotid angiogram of 3 cases with contralateral carotid compression (A; Case 1, B; Case 2, C; Case 3). Aneurysms (arrows) were located at the anterior communicating arteries $(\mathrm{ACoA})$, and directed posteriorly in all cases. The fenestrations of ACoA were not demonstrated.

能となり退院した．MRIでは右尾状核頭部に梗塞巣を認 めた。

\section{考察}

前大脳動脈に関連する血管破格は多くの報告があり, 特 に動脈瘤に合併して, 奇前大脳動脈, triplicate A2, 開密 $\mathrm{ACoA}$, 開空 $\mathrm{A} 1$, 副中大脳動脈などが報告されている ${ }^{122)}$ 


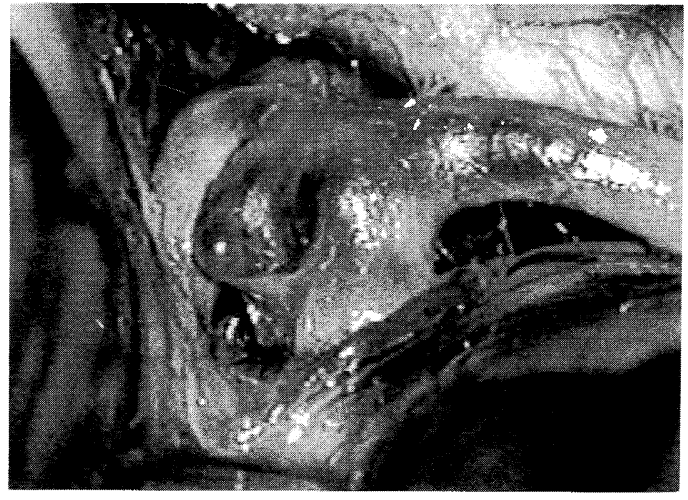

Fig. 2 Operative view and schematic drawing of Case 1 A small aneurysm was protruded from the fenes. tration of the ACoA. A large body was growing behind the right A2. After cutting the distal $\mathrm{ACoA}$, a ring clip was applied to the neck of the aneurysm.

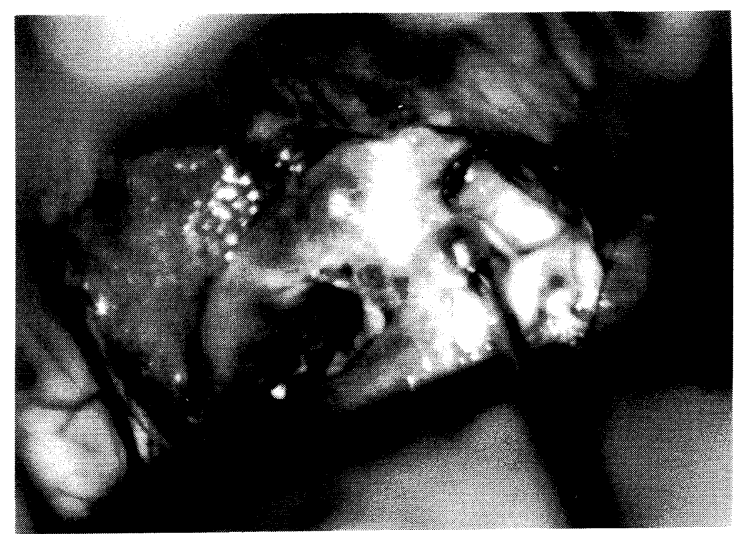

Fig. 3 Operative view and schematic drawing of Case 2. A body of aneurysm was divided by the distal $\mathrm{ACoA}$. Anterior part of aneurysm is like a blister one. Two clips were applied to each aneurysm.

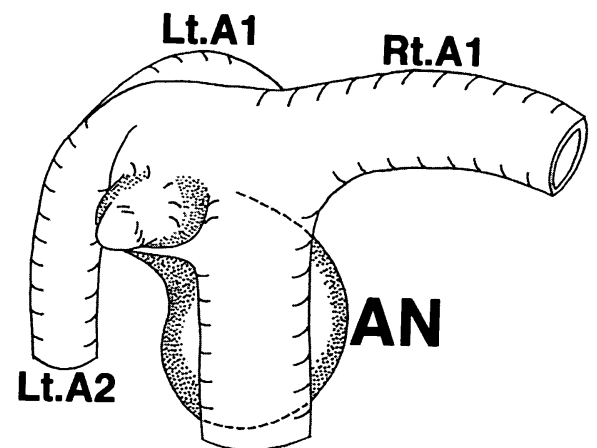

Rt.A2
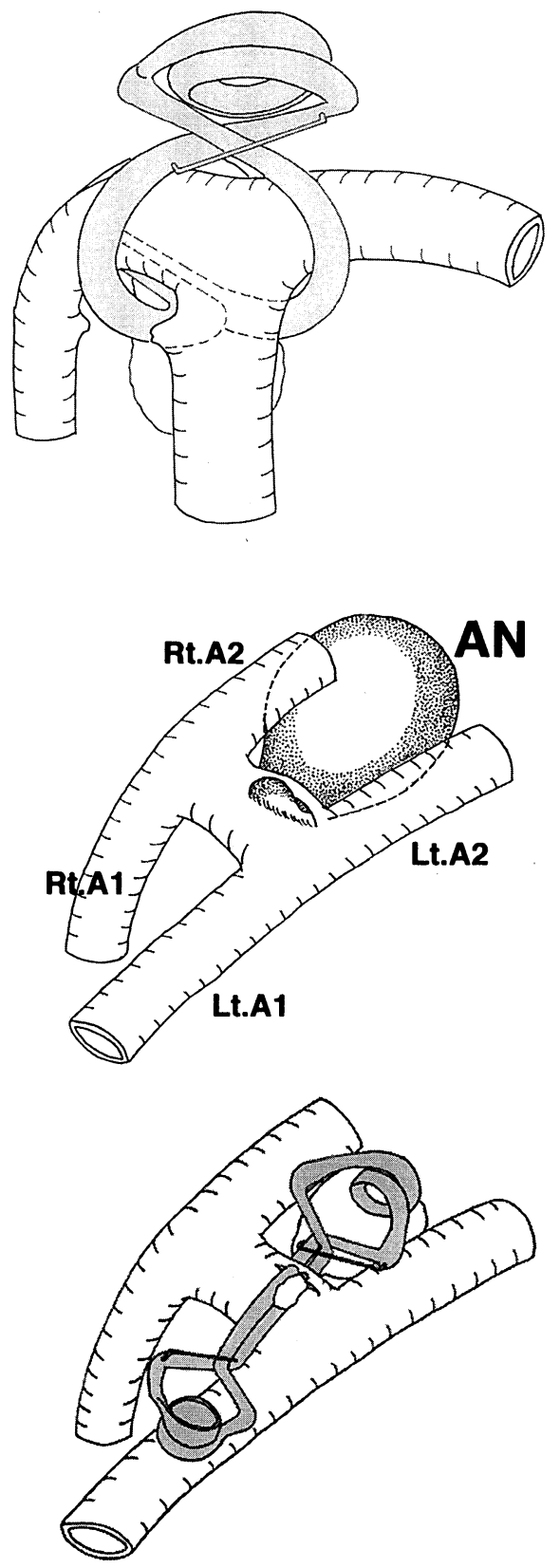


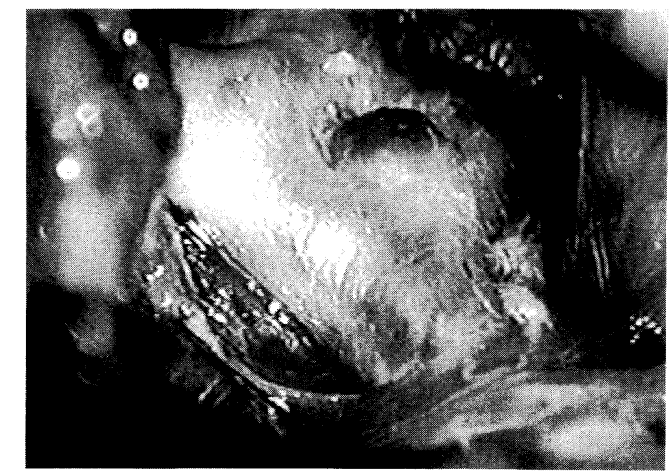

Fig. 4 Operative view and schematic drawing of Case 3. A body of aneurysm was embedding in the fenestration of the ACoA. The aneurysm and the A1 segment were trapped with 3 clips.
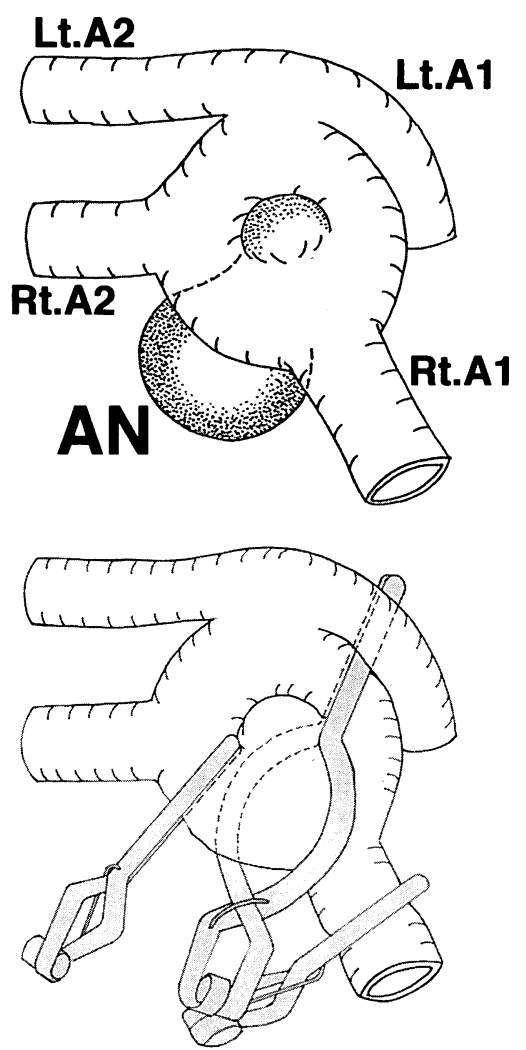

3)5)6)7)9). 一方, 前交通動脈瘤に伴う ACoA 近傍の血管破 格の頻度は 8 ～20\% と言われ，その中でも，開空形成， triplicate A2 の頻度が高い1)。前交通動脈瘤に合併する $\mathrm{ACoA}$ の開空は, $5.7 \%{ }^{5)}$ あるいは $9.7 \%^{9)}$ と報告されてい る. Kwak ら ${ }^{5)} の 296$ 例の前交通動脈瘤の報告の中で, 自 験例のような発育形態を示した 3 例が報告されている。こ のように, ACoA の開空形成は動脈瘤手術中に遭遇する ことはまれでないが，破裂動脈瘤が開空内に発育し，開空 部により動脈瘤が絞拘されている例は特殊な場合であり, 動脈瘤の処置に関して通常とは異なる手技が必要と思われ 今回，自験例をもとに検討を行った。

血管撮影上の特徵は 3 例とも, 後方に発育していること である. そのため, 通常の前後方向, 斜位, 側面撮影では $\mathrm{ACoA}$ や A1, A2 に動脈瘤が重なり, 柄部を含めて, 動 脈瘤の全貌を把握することが困難であった。ACoA の開 空が関与する場合は更に動脈瘤近傍の血管構築が複雑にな り把握しにくくなると思われる，症例 3 においては，術前 に動脈瘤の存在さえも疑われた。開空形成は, double $\mathrm{ACoA}$ のち 1 本の ACoA が 2 例とも索状であったが, 術中血流を認めた症例 3 においても, 血管撮影上確認する ことはできなかった。一般に A1, ACoAの開空は血管撮 影上，確定困難である ${ }^{9)}$.

手術所見であるが, 動脈瘤形態の特徴は, 動脈瘤は dis- tal ACoA により，体部がくびれ，開空の前後に発育し， 後方部分が大きく，破裂点も後方であったことが， 3 例に 共通することである．後方あるいは後上方向きの動脈瘤の 場合で，血管撮影で柄部が明確に描出できない場合には， ACoA の開空が関与している場合があることを念頭に置 いて手術に臨む必要があると思われる.

症例 1 は proximal $\mathrm{ACoA}$ 全体に柄部を持ち, distal $\mathrm{ACoA}$ により体部が絞拘された形をとっている，柄部の 虽離にはdistal ACoA の切断が必要と考えられたが，切 断後も結局柄部の剥離は完遂できず，開空クリップを使用 して，右 A2 を開空部に入れ，柄部を閉塞した。 Proximal $\mathrm{ACo} \mathrm{A}$ 全体に柄部を持つ場合は無理に柄部を剥離せず, 開空クリップを使用し, proximal ACoA を形成するよう に柄部を閉塞する方法が有用であると思われる ACoA の切断は clip blade の挿入空間を得るのに有用であ った。

症例 2 では開空部により動脈瘤が完全に二分されており 開空部分の瘤はないと思われた。このような場合は distal $\mathrm{ACoA}$ の切断は意味がなく，また切断は柄部近傍での操 作になるため避けるべきであり，自験例のように開空前後 の動脈瘤を別々にクリッピングする方法でよいと思われる. 症例 3 が最も困難であった例であるが, double ACoA 2 本とも同等の血流を認め, 開空内での柄部の位置の把握 

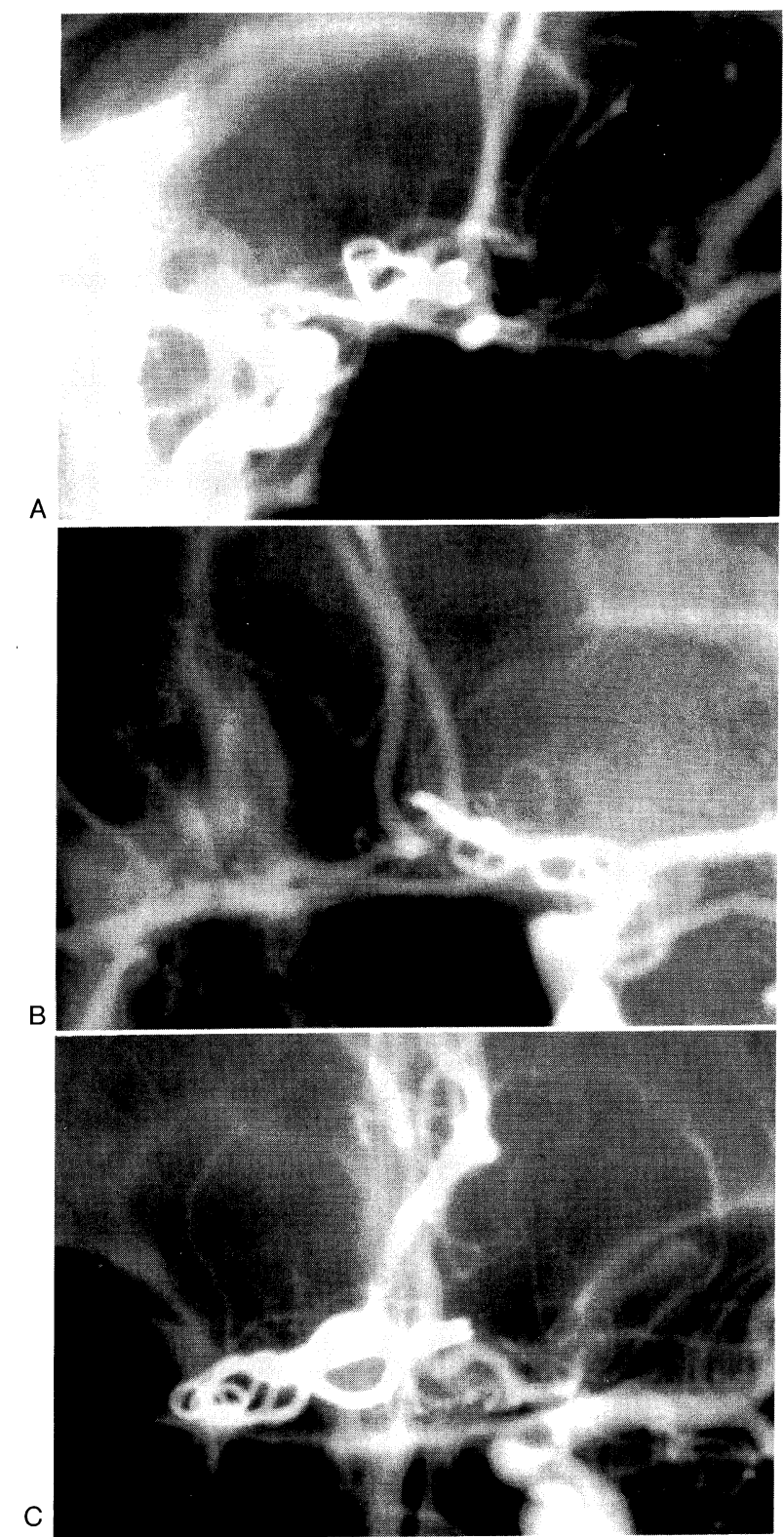

Fig. 5 Postoperative angiogram of 3 cases (A; Case 1, B; Case 2, C; Case 3). Aneurysms were well clipped in all cases.

が明確にできなかった. そのため開空内での柄部剝離操作 は出血の危険が高く，いずれか一方の $\mathrm{ACoA}$ を犠牲にし てクリッピングする必要があると思われる，この場合 ACoA からの穿通枝を認めない distal ACoA を含めての クリッピングを考慮すべきであろう。または，破裂点を含 む後方部分のみのクリッピングにとどめ, 開空部分に挟ま れた前方部分は coating あるいは wrapping にて処置する 方法も考えられる。自験例では柄部剝離中出血をきたした
ため，優位側 A1 が trapping される形となってしまった。 そのため, 両下肢の麻痺が一過性であったが, 1 カ月にわ たり継続した。このような形をとる動脈瘤は柄部クリッピ ングに固執するのは危険であると思われる.

以上, 自験例の手術法に反省も含め検討を加えた. 視床 下部穿通枝との関連, 動脈瘤の位置, A2 との関係などか ら, 後方向きは pterional approach では, 一般に難易度の 高い動脈瘤といわれており ${ }^{4)}$, 更に動脈瘤に開空が関与 すると柄部の剥離操作は distal ACoA の存在により困難 である。このような場合は開空の切断あるいは動脈瘤とと もに開空部分をクリッピングする方法を考えた方が安全で あることも念頭に置いて手術操作を行うべきであろう.

$$
\text { まと め }
$$

1. $\mathrm{ACoA}$ 開空内に発育した破裂動脈瘤の手術法につい て検討した。

2. 自験 3 例はいずれも後方あるいは後上方に向いた動脈 瘤で，体部が開空により絞拘され，破裂点は後方部分 であった。

3. 開空内での柄部剥離操作は困難であり, 開空の切断や 開空の一部を同時にクリッピングするなどの特殊な操 作が必要である。

\section{文献}

1）井上 亨, 藤井清孝, 藤原 繁, ほか：前交通動脈瘤に伴 う血管破格一手術所見・脳血管撮影・正常剖検脳からの検 討一. 脳卒中の外科 19: 19-22, 1991

2）北見公一, 上山博康, 安井信之 : 脳動脈瘤と前大脳動脈の 形態的要素およびいわゆる血管奇形との関連性について。 脳神経外科 13: 1161-1167, 1985

3) Kobayashi S, Yuge T, Sugita Y, et al: Azygos anterior cerebral artery aneurysm associated with fenestration of the anterior cerebral artery. Kurume Med J 33: 149-153, 1986

4）小林茂昭, 一八瀬良樹, 杉田虔一郎：前交通動脈瘤の手術. 解剖を中心とした考察。脳神経外科 15: 235-240, 1987

5) Kwak R, Niizuma H, Hatanaka M, et al: Anterior communicating artery aneurysms with associated anomalies. J Neurosurg 52: 162-164, 1980

6) Matsumura M, Nojiri K: Ruptured anterior communicating artery aneurysms associated with fenestration of the anterior cerebral artery. Surg Neurol 22: 371-376, 1984

7) Ogasawara $H$, Inagawa $T$, Yamamoto $M$ : Aneurysm in a fenestrated anterior cerebral artery -Case report-. Neurol Med Chir (Tokyo) 28: 575-578, 1988

8）佐藤昇樹，滝沢貴昭，佐能 昭，ほか：前交通動脈瘤クリ ッピング術における難易度の検討一pterional approachにお いて一. 脳卒中の外科 19: 30-34, 1991

9）鈴木倫保，小川 彰，嘉山孝正，ほか：前交通動脈瘤に伴 う血管奇形. 脳神経外科 16: 498-502, 1988 